\title{
SISTEM KENDALI JUMLAH ZAT PADAT TERLARUT (TDS) PADA LARUTAN NUTRISI MENGGUNAKAN ALAT CCT53200E
}

\section{CONTROL SYSTEM FOR TOTAL DISSOLVED SOLID (TDS) IN NUTRIENT SOLUTIONS USING BY CCT53200E}

\author{
Seri Intan Kuala, Yusnan Hasani Siregar, Novita Dwi Susanti \\ Pusat Penelitian Teknologi Tepat Guna Lembaga Ilmu Pengetahuan Indonesia \\ JL. K.S. Tubun No. 5 Subang, Jawa Barat \\ Email: seri.kuala.sk@gmail.com
}

\begin{abstract}
ABSTRAK
Salah satu faktor penting dalam sistem penanaman hidroponik adalah ketersediaan nutrisi yang cukup dan teratur sesuai dengan jenis, usia dan kebutuhan tanaman. Hal ini mempengaruhi kualitas dan kuantitas tanaman yang diproduksi. Kebanyakan yang terjadi sekarang pengendalian konsentrasi nutrisi secara manual dianggap kurang praktis dan efisien. Terutama untuk industri yang mempunyai standar kualitas produk yang tinggi. Tujuan penelitian ini adalah merancang sistem kendali TDS ( Total Dissolved Solid), yang merupakan indikator konsentrasi nutrisi, dalam larutan nutrisi hidroponik menggunakan CCT53200E. Metode dalam penelitian ini menggunakan kendali adaptif. Tahap pertama menghitung jumlah nutrisi dan larutan air yang dibutuhkan sebagai dasar untuk menghitung waktu aktif katup solenoid nutrisi dan air. Desain sistem kendali terdiri dari sensor ketinggian air, catu daya, sistem pengkabelan, dan antarmuka. Simulasi bertujuan untuk memvalidasi desain sistem kendali dengan keluaran berupa LED sebagai indikator aktuator yang mewakili katup solenoid. Desain dan simulasi menggunakan perangkat lunak Proteus 7.0 Free Trial. Hasil simulasi pada nilai TDS normal, TDS tinggi dan TDS rendah menunjukkan katup solenoid nutrisi dan katup solenoid air dapat bekerja berdasarkan kondisi aktual. Diharapkan desain sistem kendali ini dapat dimanfaatkan dalam industri hortikultura untuk menjaga kualitas dan kuantitas produk yang dihasilkan.
\end{abstract}

Kata kunci : CCT53200E, sistem kendali, TDS, perancangan

\begin{abstract}
One important factor in hydroponic planting systems is availability of sufficient and regular nutrition according type, age and plant needs. This affects to quality and quantity of plants produced. Currently, manual nutrition concentration control considered less practical and efficient. Especially for industries with high standards product quality. Aim of this study was design a TDS (Total Dissolved Solid) control system which is an indicator of nutrient concentration in hydroponic nutrient solutions using by CCT53200E. The method in this study used an adaptive control. The first stage calculate the amount of nutrient and water solution needed as a basis for calculating the active time of nutrient solenoid valve and water. Then designing of control system consists of water level sensor, power supply, system wiring diagram, and interface. The simulation to validation design of the control system with LED output as an actuator indicator that is called the solenoid valve. The design and simulation used Proteus 7.0 Free Trial software. Simulation results on normal TDS values, high TDS and low TDS indicate the nutrient and water solenoid valve can work based on actual conditions. It is expected the design of this control system can be utilized in the horticulture industry in maintaining the quality and quantity of the products produced.
\end{abstract}

Keywords: CCT53200E, control systems, TDS, design 


\section{PENDAHULUAN}

D erdasarkan survey BPS dari tahun 1963-2017 sebanyak 97,29 \% penduduk Indonesia mengkonsumsi sayur serta 3 dari 4 penduduk Indonesia mengkonsumsi buah (Badan Pusat Statistik, 2017). Selain itu data nilai ekspor perdagangan sayur dan buah Indonesia dari tahun 1980-2011 mengalami tren yang positif (Irawan dan Ariningsih, 2011). Data tersebut menunjukan peluang yang sangat besar untuk melakukan usaha di pertanian sayur dan buah yang termasuk kedalam jenis tanaman holtikultura (Zulkarnain, 2009). Hingga tahun 1970an sebelum hidroponik masuk ke Indonesia (Purbajanti, Slamet dan Kusmiyati, 2017), petani masih menggunakan tanah sebagai media menanam. Namun seiring peningkatan jumlah penduduk, alih fungsi lahan untuk kegiatan non pertanian sulit dihindari (Lapatandau, Rumagit dan Pakasi, 2017) bahkan cenderung meningkat dengan luas yang semakin banyak (Santosa, Adnyana dan Dinata, 2011). Siswandi dan Sarwono(2013) dalam Wahyuningsih, Fajriani dan Aini (2016) menyatakan ada alternatif yang dapat digunakan untuk meningkatkan produktifitas tanaman terutama di lahan sempit melalui sistem hidroponik. Hal ini juga didukung oleh Helmy et al. (2017) dan Hartus (2008) dalam Sarido dan Junia (2017).

Hidroponik merupakan metode bercocok tanam tanpa tanah (Siswadi dan Yuwono, 2015). Keunggulan hidroponik antara lain produksi tanaman yang higienis, pertumbuhan tanaman yang cepat dan penggunaan nutrisi yang dapat disesuaikan dengan kebutuhan tanaman (Purbajanti, Slamet dan Kusmiyati, 2017). Media tanam dapat berupa substat/agregat maupun air yang memerlukan konsentrasi nutrisi tepat. Kualitas dan kuantitas tanaman sangat bergantung pada jumlah asupan nutrisi (Suprijadi, Nuraini dan Yusuf, 2009) dan konsentrasi nutrisi (Trejo-Téllez dan Gómez-Merino, 2012) yang tepat (Maitimu dan Suryanto, 2018). Nutrisi terserap langsung oleh akar tanaman melalui media tanam (Mansyur, Triyono dan Tusi, 2014). Konsentrasi nutrisi dapat diindikasikan dari nilai TDS dengan satuan ppm ( part per million) (Rakocy et al., 2010). Kendala dalam sistem hidroponik antara lain perlu penanganan, perawatan dan pemantauan yang lebih dibanding sistem konvensional (Ibadarrohman, Salahuddin dan Kowanda, 2018). Sehingga tak jarang, ditemukan tanaman yang mengalami kekurangan mineral dan nutrisi (Rahayu, 2008) akibat naik turunnya konsentrasi nutrisi dan mineral. Jika tanaman kekurangan unsur hara maka pertumbuhan akar, batang atau daun akan terlambat dan abnormal (Wiraatmaja, 2017). Untuk mencegah hal ini, dilakukan pengendalian dan monitoring secara rutin oleh petani. Namun pengendalian ini masih dilakukan secara manual (Crisnapati et al., 2017). Pengendalian manual memiliki kekurangan kapan kadar nutrisi sudah mulai berkurang (Safura, Kirom dan Suhendi, 2018).

Kemajuan teknologi dianggap mampu memberi solusi melalui perancangan sistem kendali jumlah zat padat terlarut (TDS) pada larutan nutrisi secara otomatis dengan metode kendali adaptif. Metode ini dipilih karena dapat secara otomatis menyesuaikan kembali ke pengaturan mode kendali (Wahjudi, 2018). Ibrahim, Solahudin dan Widodo (2015), Melvix dan Sridevi (2014) serta Prathisthaya, Liyantono dan Solahudin(2014) telah melakukan penelitian mengenai kendali nutrisi yang diindikasikan dengan nilai EC (electrical conductivity). Berbeda dengan sebelumnya, dalam penelitian ini kendali nilai TDS pada bak penampung campuran larutan nutrisi dilakukan sebelum larutan nutrisi didistribusikan keseluruh sistem. Tujuan dari penelitian ini adalah merancang sistem kendali TDS untuk memudahkan pengoperasian hidroponik. Selain itu untuk pengusaha holtikultura, diharapkan biaya produksi dapat ditekan karena tidak perlu biaya tambahan tenaga kerja untuk memantau konsentrasi nutrisi secara terus menerus karena telah digantikan oleh sistem. Dengan sistem kendali otomatis nilai nutrisi tanaman tetap terjaga selama 24 jam. 


\section{BAHAN DAN METODE}

\section{Waktu dan Tempat}

Penelitian dilakukan pada bulan Juli hingga Agustus 2016. Kegiatan pengambilan data, simulasi, pengolahan dan penyusunan karya tulis ilmiah dilakukan di Pusat Pengembangan Teknologi Tepat Guna LIPI -Subang, Jawa Barat.

\section{Bahan dan Alat}

Bahan yang digunakan dalam penelitian adalah nutrisi hidroponik dan air. Sedangkan alat yang digunakan meliputi alat CCT53200E, katup selenoid12 VDC, relay 5 V, pewaktu, bak penampung campuran larutan nutrisi, wadah larutan nutrisi, toren air, gelas ukur, pengaduk, timbangan dan perangkat lunak Proteus 7.0 Free Trial.

\section{Metodologi}

Kegiatan penelitian dibagi menjadi beberapa tahapan yaitu : perhitungan jumlah kebutuhan larutan nutrisi dan air, perhitungan lama bukaan katup solenoid larutan nutrisi dan katup solenoid air, perancangan sistem kendali dan simulasi sistem kendali hidroponik.

\section{Perhitungan Jumlah Kebutuhan Larutan Nutrisi dan Air}

Jumlah larutan nutrisi dan air didasarkan pada kebutuhan larutan siap pakai perminggu pada sistem hidroponik DFT(Deep Film Technique) PPTTG LIPI Subang sebanyak \pm 40.000ml. Selama ini pencampuran dilakukan dengan metode kira-kira yaitu dengan menambahkan larutan nutrisi sedikit demi sedikit kedalam sejumlah air hingga mencapai nilai TDS yang diinginkan. Metode ini kurang efektif sehingga perlu dilakukan uji coba untuk memperoleh perhitungan baku yang dapat digunakan secara tetap. Sebanyak $20 \mathrm{~mL}$ larutan nutrisi berTDS 1390 ppm ditambahkan bertahap kedalam 1000 mL air ber-TDS 125,5 ppm. Kemudian nilai TDS larutan campuran tersebut diukur hingga mendekati nilai yang diinginkan untuk memperoleh nilai rata-rata kenaikan nilai. Nilai rata-rata ini dijadikan pembagi untuk nilai TDS yang ingin dicapai guna mengetahui berapa banyak larutan nutrisi yang harus ditambahkan kedalam larutan.

\section{Perhitungan Lama Bukaan Katup Solenoid Larutan Nutrisi dan Katup Solenoid Air}

Wadah larutan nutrisi berbentuk silinder dengan lubang disisi bawah (Gambar 1) dengan ketinggian $40 \mathrm{~cm}$. Kecepatan aliran yang keluar dari wadah larutan nutrisi dan kemudian masuk ke bak penampung campuran larutan nutrisi dapat dihitung menggunakan persamaan gerak jatuh bebas seperti pada Persamaan 1 (Technical Learning College, 2018 dan Kuphaldt, 2009). Kecepatan aliran yang keluar dari wadah larutan perlu diketahui agar perhitungan debit aliran dan waktu bukaan katup selenoid dapat diperoleh. Lama waktu bukaan katup selenoid diperhitungkan menggunakan Persamaan 2 (Widodo et al., 2016 dan Harianja dan Rosa, 2011).

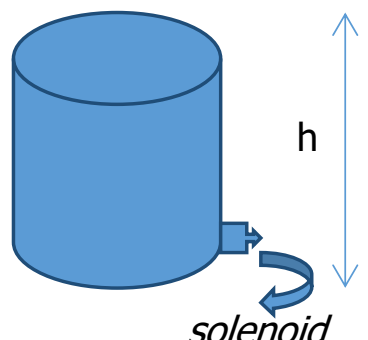

Gambar 1. Wadah Larutan Nutrisi

24 Seri Intan Kuala, Yusnan Hasani Siregar, Novita Dwi Susanti Sistem Kendali Jumlah Zat Padat Terlarut (TDS) pada Larutan Nutrisi Menggunakan Alat CCT53200E 


$$
v=\sqrt{2 g h}
$$

Dimana:

$\mathrm{v}=$ kecepatan $(\mathrm{m} /$ detik $)$

$\mathrm{g}=$ percepatan gravitasi $\left(9.8 \mathrm{~m} /\right.$ detik $\left.^{2}\right)$

$\mathrm{h}=$ tinggi bak $(\mathrm{m})$

Dimana:

$$
t=\frac{v}{\varnothing}
$$

$\mathrm{t}=$ waktu bukaan katup katup selenoid (detik)

$\mathrm{V}=$ volume (liter)

$\emptyset=\operatorname{debit}\left(\mathrm{m}^{3} /\right.$ detik $)$

Lama bukaan katup selenoid air juga diperhitungkan dengan cara yang sama. Pengisian air kedalam bak pencampur berasal dari wadah penampung air berbentuk silinder dengan tinggi $50 \mathrm{~cm}$ yang dilewatkan menggunakan pipa plastik. Letak bak penampung, wadah penampung air dan jaringan perpipaan terlihat pada Gambar 2. Pipa plastik membentuk aliran halus dengan konstanta Roughness $\varepsilon=0$ dan aliran laminar dengan bilangan Reynold kurang dari 2100 (Moran et al., 2002).

Menghitung kecepatan air yang masuk kedalam bak penampung menggunakan analisis aliran pipa seperti pada Persamaan 3 (Moran et al., 2002 dengan penyesuaian).

$$
0.3647 V_{2}{ }^{2}+0.0294 V_{2}-1=0
$$

Dimana :

$\mathrm{V}_{2}=$ Kecepatan air pada bak penampung $(\mathrm{m} /$ detik $)$

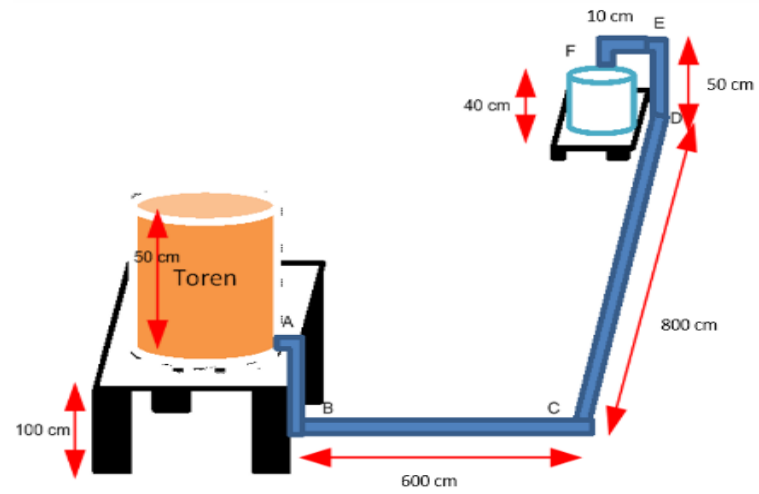

Gambar 2. Perpipaan pada Sistem Kendali Jumlah Zat Padat Terlarut pada Larutan Nutrisi

\section{Perancangan Sistem Kendali}

Gambar 3 menunjukkan diagram alir kendali jumlah zat padat terlarut nutrisi pada larutan nutrisi hidroponik. Pada tahap ini juga merancang sistem kendali yang terdiri dari perancangan sensor ketinggian air beserta catu dayanya dan perancangan diagram pengkabelan keseluruhan sistem kendali jumlah zat padat terlarut beserta antar mukanya. Untuk validasi seluruhan sistem yang telah dirancang, dilakukan simulasi menggunakan perangkat lunak Proteus 7.0 Free Trial dengan keluaran berupa LED sebagai pengganti aktuator berupa katup selenoid. 


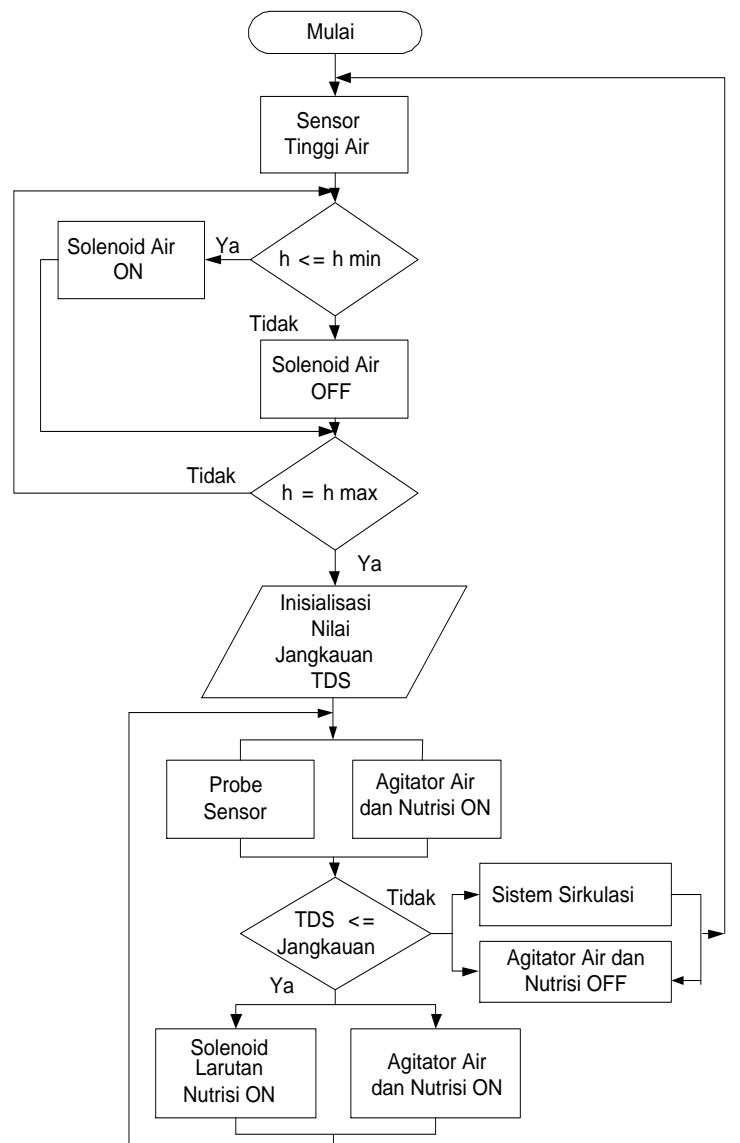

Gambar 3. Diagram Alir Sistem Kendali Jumlah Zat Padat Terlarut

\section{HASIL DAN PEMBAHASAN}

\section{Perbandingan Jumlah Kebutuhan Larutan Nutrisi dan Air}

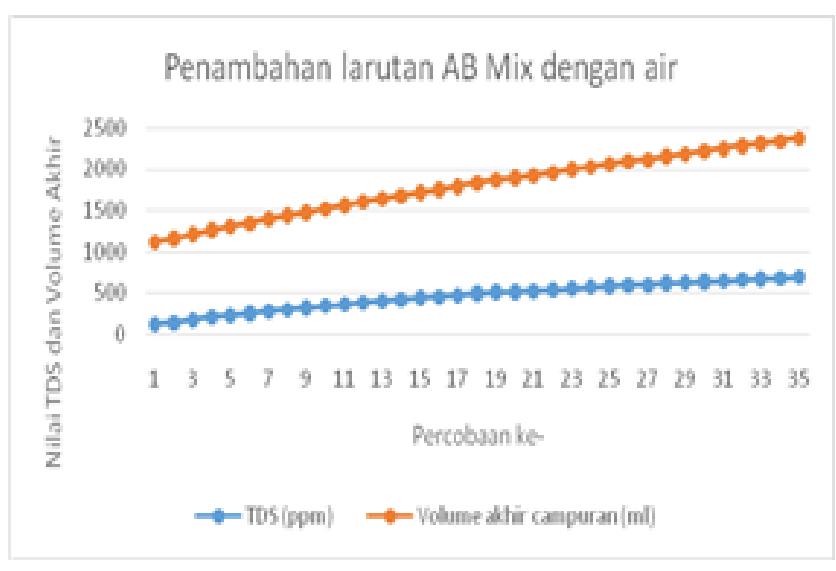

Gambar 4. Penambahan Larutan Nutrisi Dengan Air

Dari prosedur yang dilakukan diperoleh rata-rata kenaikan TDS setiap $20 \mathrm{~mL}$ adalah 16.7 ppm (Gambar 4). Sehingga untuk memperoleh TDS 1050 ppm sesuai nilai yang ditetapkan perancangan dilakukan penambahan larutan nutrisi sebanyak $1256 \mathrm{~mL}$ atau 63 kali. Jumlah kebutuhan larutan nutrisi dan air sebanyak 22,269 liter dan 17,730 liter untuk mendapatkan $40.000 \mathrm{~mL}$ larutan siap pakai dengan TDS 1050 ppm. 


\section{Lama Bukaan Katup Solenoid Nutrisi dan Katup Solenoid Air}

Dengan konstanta percepatan gravitasi bumi sebesar $\mathrm{g}=9,8 \mathrm{~m} /$ detik $^{2}$ (Hadi, 2012) diperoleh kecepatan aliran dari wadah larutan nutrisi sebesar 2,8 $\mathrm{m} /$ detik. Dengan diameter katup katup selenoid sebesar $1,5 \mathrm{~cm}$ diketahui debit aliran yang keluar dari katup selenoid sebanyak 0,00049455 $\mathrm{m}^{3} /$ detik. Lama bukaan katup selenoid nutrisi adalah 45,02 detik yang akan ditetapkan nilainya pada pewaktu. Waktu bukaan katup selenoid wadah penampung air diperoleh sebesar 18,1 detikyang juga akan ditetapkan nilainya pada pewaktu.

\section{Sistem Kendali Jumlah Zat Padat Terlarut Nutrisi}

Hasil rancangan sensor ketinggian air beserta catu dayanya terlihat pada Gambar 5. Sensor ketinggian air dipasang pada bak penampung campuran larutan nutrisi untuk memastikan ketersedian campuran larutan nutrisi selalu ada.

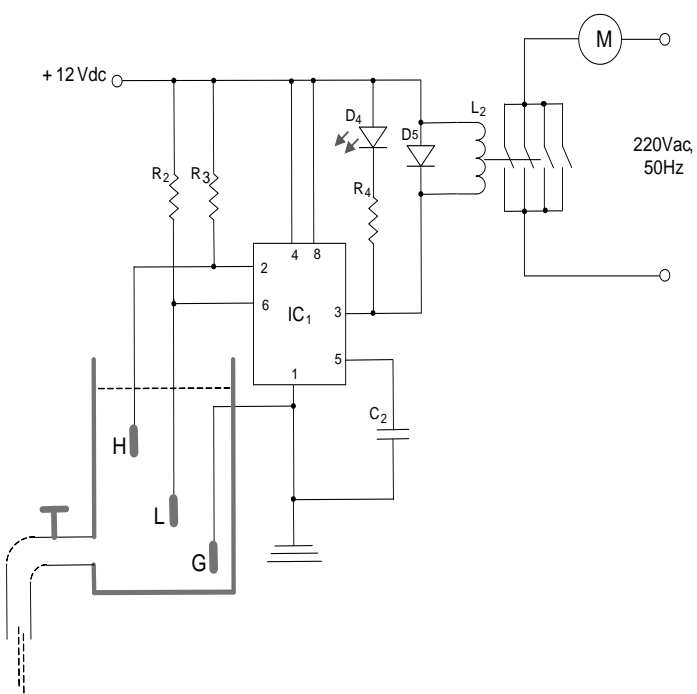

Gambar 5. Skema Rancangan Rangkaian Sensor Ketinggian Air

Agar sensor ketinggian air dapat bekerja dengan baik maka diperlukan sebuah catu daya sebesar 12 Volt. Gambar 6 menunjukan skema rancangan sumber tegangan 12 Voltyang telah dibuat.

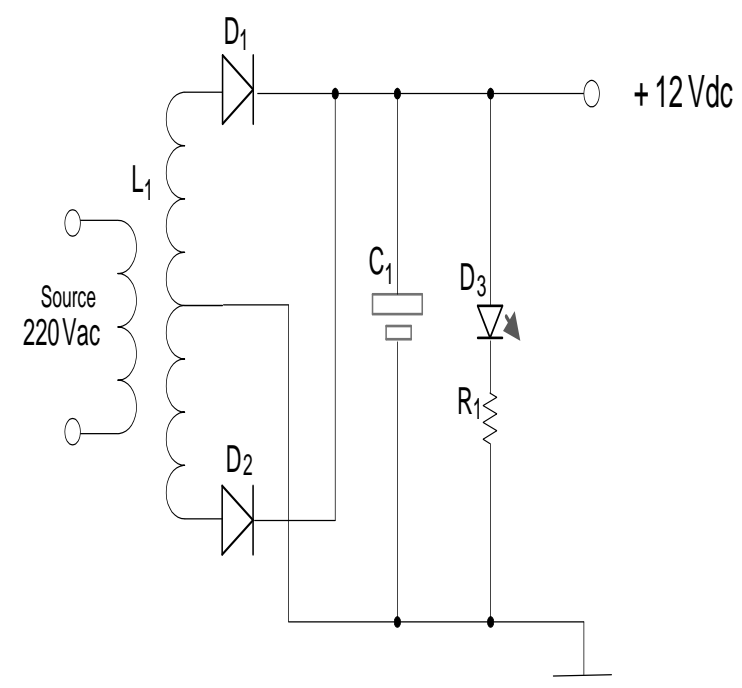

Gambar 6. Skema Rancangan Rangkaian Catu Daya 12V, 300ma Sensor Ketinggian Air 
Gambar 7 menunjukan diagram pengkabelan keseluruhan sistem kendali jumlah zat padat terlarut pada larutan nutrisi hidoponik. Untuk menjaga keberlangsungan sistem kendali saat terjadi kerusakan komponen, sistem ini dibuat secara manual dan otomatis.

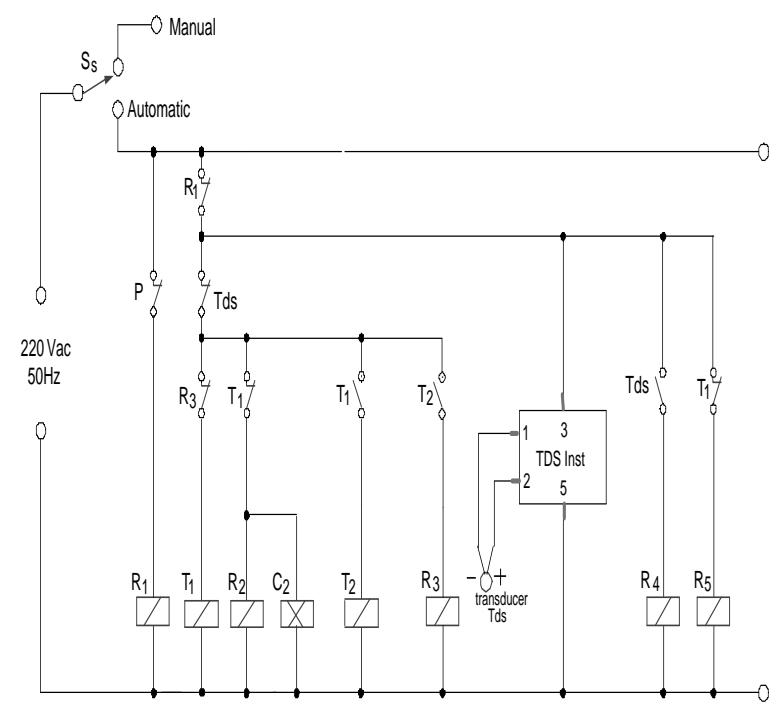

Gambar 7. Diagram Pengkabelan Sistem Keseluruhan

Untuk memudahkan operasi pengendalian sistem oleh pengguna baik masukan, keluaran maupun indikator sistem yang sedang berjalan dirancang sebuah diagram pengkabelan seperti yang telihat pada Gambar 8.

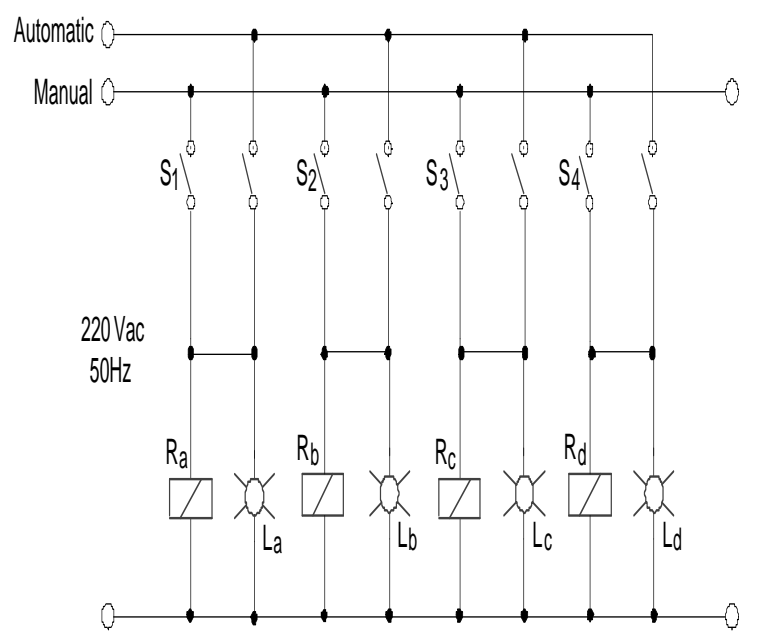

Gambar 8. Diagram Pengkabelan Sistem Antar Muka

\section{Hasil Simulasi Sistem Kendali Hidroponik}

Simulasi dirancang dengan beberapa kondisi yang mewakili kondisi nyata yaitu kondisi saat nilai TDS normal (sesuai nilai TDS yang ditentukan), TDS tinggi (nilai TDS lebih tinggi dari nilai TDS yang ditentukan) dan TDS rendah (nilai TDS lebih rendah dari nilai TDS yang ditentukan). Alat CCT53200E ditentukan pada jangkauan 1010 ppm - 1090 ppm. Batas bawah merupakan batas minimal konsentrasi nutrisi yang dibutuhkan (1010 ppm) dan batas atas merupakan batas maksimal konsentrasi nutrisi yang dibutuhkan (1090 ppm). Dalam simulasi, lampu LED warna kuning sebagai indikator katup selenoid penampung air sedangkan LED warna hijau untuk katup selenoid nutrisi. Sensor melakukan pengukuran terus menerus dan 
nilainya diproses oleh pengendali agar sesuai dengan nilai batas atas (nilai TDS tertinggi) dan bawah (nilai TDS terendah) yang telah ditentukan.

Kondisi normal terjadi apabila hasil pembacaan perangkat CCT53200E berada pada nilai antara 1010 ppm-1090 ppm dengan kondisi katup katup selenoidair maupun nutrisi tertutup sehingga tidak ada LED yang menyala (Gambar 9). Jika hasil pengukuran alat CCT53200E diatas 1090 ppm maka sistem akan mengaktifkan Relay1 selama 18,1 detik untuk membuka katup selenoid penampung air. Kondisi ini diperlihatkan pada Gambar 10 dengan lampu LED berwarna kuning yang menyala sebagai indikasi katup selenoid aktif. Sedangkan jika hasil pengukuran dibawah 1010 ppm maka sistem akan mengaktifkan Relay2 (RL2) selama 22,7 detik untuk membuka katup selenoid wadah larutan nutrisi. Gambar 11 menunjukkan nilai TDS rendah dengan aktifnya LED warna hijau sebagai indikasi katup katup selenoid nutrisi terbuka.

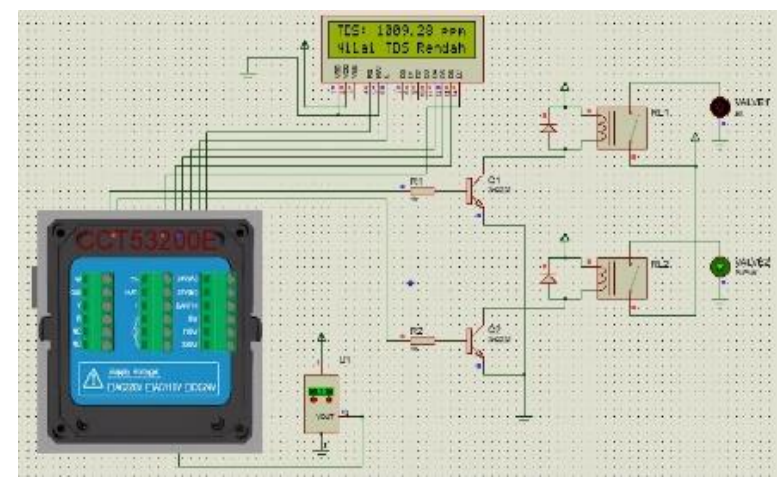

Gambar 9. Kondisi Nilai TDS Normal

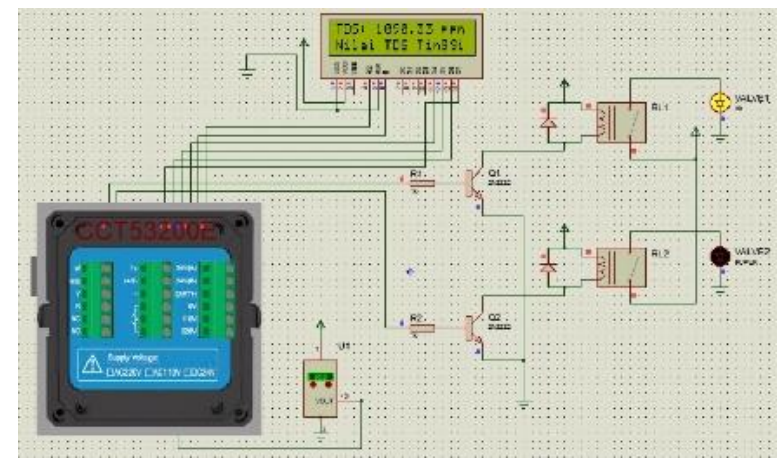

Gambar 10. Kondisi Nilai TDS Tinggi

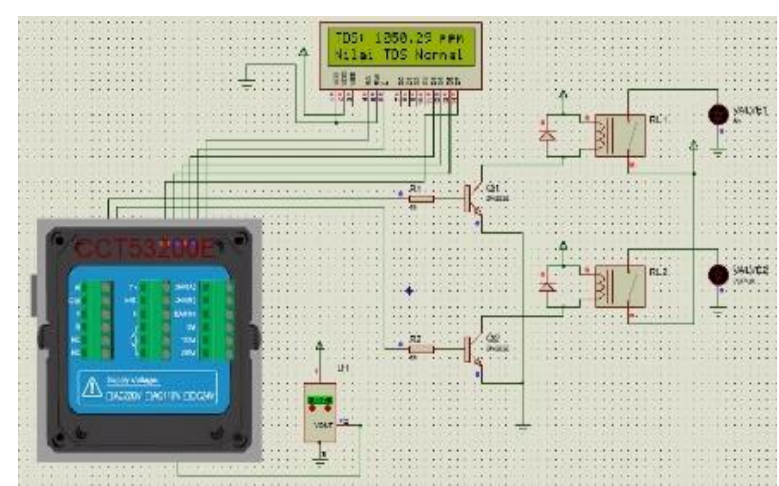

Gambar 11. Kondisi Nilai TDS Rendah 


\section{KESIMPULAN}

Dari hasil simulasi diperoleh sistem dapat bekerja dengan baik sesuai kondisi nyata pembacaan nilai TDS. Dari hasil perancangan dapat disimpulkan bahwa perhitungan jumlah larutan nutrisi dan air yang masuk dalam sistem perlu dilakukan untuk menjaga konsentrasi awal larutan siap pakai. Lamanya katup selenoid aktif berpengaruh terhadap volume yang masuk dalam sistem. Makin lama katup selenoid aktif makin banyak volume yang masuk kedalam bak penampung dan hal itu berpengaruh terhadap naik dan turunnya nilai TDS larutan nutrisi. Dengan adanya sistem kendali ini diharapkan dapat dimanfaatkan pengguna khususnya petani di bidang industri holtikultura yang menghadapi permasalahan serupa. Sistem ini masih harus disempurnakan kembali dengan menambahkan berbagai parameter yang mempengaruhi pertumbuhan tanaman dalam sistem hidroponik.

\section{UCAPAN TERIMAKASIH}

Terimakasih kepada Umi Hanifah, Aidil Haryanto, Teguh Santoso, Edi Sasongko, Galih Ryan Basuki, Maulana Furqon, Dadang Gandara, Iman Rusim, Roni, Andi Taufan, Ari Rahayuningtyas dan semua rekan-rekan civitas PPTTG LIPI yang telah membantu dalam pembuatan karya tulis ilmiah ini.

\section{DAFTAR PUSTAKA}

Badan Pusat Statistik (2017) Konsumsi Buah dan Sayur Susenas maret 2016.

Crisnapati, P. N. et al. (2017) 'Hommons: Hydroponic management and monitoring system for an IOT based NFT farm using web technology', in 2017 th International Conference on Cyber and IT Service Management, CITSM 2017. doi: 10.1109/CITSM.2017.8089268.

Fluid Mechanics: Continuining Education Profesional Development Course (2018). Available at: http://www.tlch2o.com/PDF/FuildsASS.pdf.

Hadi, R. M. (2012) Laporan Penelitian Menghitung Percepatan Gravitasi dengan Menggunakan Bandul Matematis dengan Metode Kuadrat Terkecil. Banduing. Available at : chromeextension://oemmndcbldboiebfnladdacbdfmadadm/https://s3.amazonaws.com/academ ia.edu.documents/33243691/Laporan_Penelitian_-

_Menghitung_Percepatan_Gravitasi_dengan_Menggunakan_Bandul_Matematis_dengan Metode_Kuadrat_Terkecil.pdf?AWSAccessKeyId=AKIAIWO.

Harianja, J. A. and Rosa, N. A. P. (2011) 'Pengaruh Perubahan Debit Terhadap Pergerakan Sedimen', Majalah IImiah UKRIM, (2).

Helmy et al. (2017) Nutrient Film Technique (NFT) Hydroponic Monitoring System Based on Wireless Sensor Network. IEEE.

Ibadarrohman, Salahuddin, N. S. and Kowanda, A. (2018) 'Sistem Kontrol dan Monitoring Hidroponik berbasis Android', in STMIK ATMA LUHUR Pangkalpinang, pp. 8-9.

Ibrahim, R., Solahudin, M. and Widodo, S. (2015) 'Control System for Nutrient Solution of Nutrient Film Technique Using Fuzzy Logic', TELKOMNIKA Indonesian Journal of Electrical Engineering, 13, pp. 1281-1288. doi: 10.12928/telkomnika.v13i4.2113.

Irawan, B. and Ariningsih, E. (2011) Agribisnis Sayuran dan Buah: Peluang Pasar, Dinamika Produksi dan Strategi Peningkatan Daya Saing. Available at: chromeextension://oemmndcbldboiebfnladdacbdfmadadm/http://www.litbang.pertanian.go.id/ buku/memperkuat_dayasaing_produk_pe/BAB-III-3.pdf.

Kuphaldt, T. R. (2009) Lessons In Industrial Instrumentation. 4th edn. Available at: www.PAControl.com.

Lapatandau, Y. A., Rumagit, G. A. J. and Pakasi, C. B. D. (2017) 'Alih Fungsi Lahan Pertanian

30 Seri Intan Kuala, Yusnan Hasani Siregar, Novita Dwi Susanti Sistem Kendali Jumlah Zat Padat Terlarut (TDS) pada Larutan Nutrisi Menggunakan Alat CCT53200E 
di Kabupaten Minahasa Utara', Agri-SocioEkonomi Unsrat, 13(2), pp. 1-8. Available at: chrome-

extension://oemmndcbldboiebfnladdacbdfmadadm/https://media.neliti.com/media/publ ications/76119-ID-alih-fungsi-lahan-pertanian-di-kabupaten.pdf.

Maitimu, D. K. and Suryanto, A. (2018) 'Pengaruh Media Tanam dan Konsentrasi AB-Mix pada Tanaman Kubis Bunga (Brassica oleraceae var botrytis L.) Sistem Hidroponik Substrat', Jurnal Produksi Tanaman, 6(4), pp. 516-523.

Mansyur, A. N., Triyono, S. and Tusi, A. (2014) 'Pengaruh Naungan terhadap Pertumbuhan Sawi (Brassica Juncea L.) pada Sistem Hidroponik DFT (Deep Flow Technique)', Jurnal Teknik Pertanian LampungVol, 3(2), pp. 103-110.

Melvix, L. J. S. and Sridevi, C. (2014) 'Design of efficient hydroponic nutrient solution control system using soft computing based solution grading', in 2014 International Conference on Computation of Power, Energy, Information and Communication (ICCPEIC). IEEE, pp. 148-154. doi: 10.1109/ICCPEIC.2014.6915356.

Moran, M. J. et al. (2002) Introduction to Thermal Systems Engineering: Thermodynamics, Fluid Mechanics and Heat Transfer. John Wilet and Sons, Inc. Available at: https://docs.zoho.com/file/2bvxi621225b3e2b8447392f8f4993349feba.

Prathisthaya, M. E., Liyantono and Solahudin (2014) 'Rancang Bangun Sistem Kendali Proportional Integral-Derivative pada Pengendalian Konsentrasi Larutan Nutrisi Hidroponik', in Seminar Nasional FTIP UNPAD _ PERTETEA - HIPI . Jatinangor: UNPAD PRESS, pp. 376-384. Available chromeextension://oemmndcbldboiebfnladdacbdfmadadm/https://repository.ipb.ac.id/bitstrea $\mathrm{m} /$ handle/123456789/74873/Semnas Perteta Unpad_LYN_3.pdf?sequence $=1$ \&isAllowed $=y$.

Purbajanti, E. D., Slamet, W. and Kusmiyati, F. (2017) Hydroponic Bertanam tanpa Tanah. Pertama. Semarang: EF Press Digimedia.

Rahayu, W. R. K. (2008) Perancangan aplikasi Sistem Pakar untuk Mendiagnosa Defisiensi Nutrisi Tanaman pada Hidroponik Pertanian Berbasis WEB. Universitas Islam Negeri Malang.

Rakocy, J. E. et al. (2010) Update on Tilapia and Vegetable Production in The Uvi Aquaponic System. Available

at: https://www.researchgate.net/publication/237308635_Update_on_tilapia_and_vegetab le_production_in_the_UVI_aquaponic_system.

Safura, S. A. El, Kirom, M. R. and Suhendi, A. (2018) 'Rancang Bangun Sistem Kontrol Logika Fuzzy pada Pengaturan Konsentrasi Nutrisi Hidroponik dengan Metoda Pengairan Nutrient Film Technique', in e-Proceeding of Engineering, pp. 959-966.

Santosa, I. G. N., Adnyana, G. M. and Dinata, I. K. K. (2011) 'Dampak Alih Fungsi Lahan Sawah Terhadap Ketahanan Pangan Beras', in Prosiding Seminar Nasional Budidaya Pertanian. Bengkulu, pp. 1-11. Available chromeextension://oemmndcbldboiebfnladdacbdfmadadm/https://core.ac.uk/download/pdf/35 319562.pdf.

Sarido, L. and Junia (2017) 'Uji Pertumbuhan dan Hasil Tanaman Pakcoy (Brassica Rapa L.) dengan Pemberian Pupuk Organik Cair pada System Hidroponik', Jurnal AGRIFOR, 16(1), pp. 65-74.

Siswadi and Yuwono, T. (2015) 'Pengaruh Macam Media Terhadap Pertumbuhan dan Hasil Selada ( Lactuca Sativa L) Hidroponik', Jurnal Agronomika, 09(03), pp. 257-264. Available http://download.garuda.ristekdikti.go.id/article.php?article $=296580 \& v a l=5171 \&$ title $=P$ ENGARUH MACAM MEDIA TERHADAP PERTUMBUHAN DAN HASIL SELADA ( Lactuca sativa L) HIDROPONIK. 
Suprijadi, Nuraini, N. and Yusuf, M. (2009) 'Sistem Kontrol Nutrisi Hidroponik dengan menggunakan Logika Fuzzy', Ktrl.Inst (J.Auto.Ctrl.Inst), 1(1), pp. 31-35. Available at: chrome-

extension://oemmndcbldboiebfnladdacbdfmadadm/https://personal.fmipa.itb.ac.id/sup ri/files/2009/02/JOKI_Th20091_SH_NN.pdf.

Trejo-Téllez, L. I. and Gómez-Merino, F. C. (2012) 'Nutrient Solutions for Hydroponic Systems', in Asao, F. C. G.-M. and ED1 - Toshiki (eds) Hydroponics. Rijeka: IntechOpen, p. Ch. 1. doi: $10.5772 / 37578$.

Wahjudi, R. S. (2018) 'Perancangan Sistem Kendali pada Kendalian yang Disertai Ketidak Pastian', in Seminar Nasional Pakar ke 1, pp. 399-404.

Wahyuningsih, A., Fajriani, S. and Aini, N. (2016) 'Komposisi Nutrisi Dan Media Tanam Terhadap Pertumbuhan Dan Hasil Tanaman Pakcoy (Brassica Rapa L.) Sistem Hidroponik', Jurnal Produksi Tanaman, 4(8), pp. 595-601.

Widodo, S., Suharno, K. and Salahudin, X. (2016) 'Analisis Aliran Air dalam Pipa Bercabang (Junction)', UNTIDAR, pp. 77-84. Available at: jurnal.untidar.ac.id/index.php/wahana/article/view/252/205.

Wiraatmaja, I. W. (2017) Defisiensi dan Toksisitas Hara Mineral serta Responnya terhadap Hasil. Denpasar. Available at: chromeextension://oemmndcbldboiebfnladdacbdfmadadm/https://simdos.unud.ac.id/uploads/f ile_pendidikan_1_dir/8845246192c4d15f3aa034af1b88a4d4.pdf.

Zulkarnain, Z. (2009) Dasar-Dasar Hortikultura. 